\section{JURNAL EKONOMI EFEKTIF}

ISSN : $2622-8882$, E-ISSN : 2622-9935

Jurnal Ekonomi Efektif, Vol. 4, No. 2, Januari 2022 @Prodi Manajemen Fakultas Ekonomi

Universitas Pamulang

\title{
PENGARUH MOTIVASI INTRINSIK TERHADAP KINERJA PEGA WAI PADA BADAN PUSAT STATISTIK KOTA TANGERANG SELATAN
}

\author{
Haryanto $^{1}$, Mukrodi ${ }^{2 *}$ \\ Universitas Pamulang, Tangerang Selatan, Banten, Indonesia \\ harysabtu1710@gmail.com ${ }^{1}, \underline{\text { dosen00560@ unpam.ac.id }}{ }^{2 *}$
}

\begin{abstract}
Manuskrip: November -2021; Ditinjau: November: -2021; Diterima: Desember-2021; Online: Januari -2022;
\end{abstract} Diterbitkan: Januari-2022

\begin{abstract}
ABSTRAK
Penelitian ini bertujuan untuk mengetahui pengaruh motivasi intrinsik terhadap kinerja pegawai pada Badan Pusat Statistik Kota Tangerang Selatan. Metode yang digunakan adalah explanatory research dengan sampel sebanyak 85 responden. Teknik analisis menggunakan analisis statistik dengan pengujian regresi, korelasi, determinasi dan uji hipotesis. Hasil penelitian ini variabel motivasi intrinsik diperoleh nilai rata-rata skor sebesar 3,396 dengan kriteria baik. Variabel kinerja pegawai diperoleh nilai rata-rata skor sebesar 3,804 dengan kriteria baik. Motivasi intrinsik berpengaruh positif dan signifikan terhadap kinerja pegawai dengan nilai persamaan regresi $\mathrm{Y}=11,111+0,793 \mathrm{X}$, dan nilai koefisien korelasi 0,749 atau memiliki tingkat hubungan yang kuat dengan nilai determinasi 56,1\%. Uji hipotesis diperoleh signifikansi $0,000<0,05$.
\end{abstract}

\section{Kata Kunci: Motivasi Intrinsik, Kinerja Pegawai}

\section{ABSTRACT}

This study aims to determine the effect of intrinsic motivation on employee performance at the Central Bureau of Statistics of South Tangerang City. The method used is explanatory research with a sample of 85 respondents. The analysis technique uses statistical analysis with regression, correlation, determination and hypothesis testing. The results of this study of intrinsic motivation variable obtained an average score of 3,396 with good criteria. Employee performance variable obtained an average score of 3.804 with good criteria. Intrinsic motivation has a positive and significant effect on employee performance with the value of the regression equation $Y=11.111+0.793 X$, and the value of the correlation coefficient is 0.749 or has a strong relationship with a determination value of 56.1\%. Hypothesis testing obtained a significance of $0.000<0.05$.

Keywords: Intrinsic Motivation, Employee Performance 


\section{PENDAHULUAN}

\section{A. Latar Belakang}

Penetapan program reformasi birokrasi oleh pemerintah menunjukkan keseriusan pemerintah untuk melakukan perubahan. Badan Pusat Statistik (BPS) sebagai salah satu instansi pemerintah non departemen juga telah menetapkan program reformasi birokrasi. Visi, Misi, dan Core Value untuk insan statistik (karyawan BPS) telah ditetapkan dan tujuan berjangka juga telah disusun.

Pelaksanaan pencapaian visi, misi dan tujuan tersebut bukanlah sesuatu hal yang mudah, berbagai macam kendala, hambatan dan tantangan akan dan telah dilalui. Salah satu tantangan yang dihadapi BPS dalam mencapai visi tersebut adalah sumber daya manusia, dibutuhkan sumber daya manusia dengan kinerja tinggi, tangguh dan berkualitas, yang mau dan mampu bekerja bersama dalam harmoni lingkungan BPS dengan penuh kesungguhan.

BPS juga menyusun Standard Operational Procedure (SOP) yang wajib dipedomani oleh seluruh karyawan BPS. SOP disusun agar setiap kegiatan berjalan sesuai dengan tujuan yang ditetapkan dengan focus SOP adalah target sampel, waktu, dan metodologi. Ada pekerjaan/survei yang sifatnya mingguan, bulanan, triwulanan, subround, semesteran, dan tahunan.

Jadwal yang bersamaan pada beberapa kegiatan survei seringkali terjadi, namun hal ini tidak boleh dijadikan alasan bagi karyawan untuk terlambat dalam menyelesaikan pekerjaan. Karakteristik dan kompleksitas pekerjaan yang berbeda menuntut setiap karyawan untuk memberdayakan diri dan mencari pemecahan masalah-masalah di lapangan, tetapi tidak boleh menyimpang dari SOP.

Kepadatan, karakteristik, dan kompleksitas pekerjaan tersebut menuntut karyawan memiliki kinerja yang tinggi, sehingga diharapkan pekerjaan akan berjalan sesuai dengan SOP yang ditetapkan. Tanggung jawab penyelesaian pekerjaan yang cukup berat tersebut tentunya tidak akan bisa dilakukan oleh karyawan yang tidak termotivasi.

Tanggung jawab penyelesaian pekerjaan yang cukup berat tersebut tentunya juga tidak akan bisa dilakukan oleh karyawan yang tidak bekerja dengan disiplin. Disiplin kerja terhadap waktu memberikan kemungkinan besar terhadap hasil kerja yang baik dan menghindari pemborosan terhadap energi yang dikeluarkan organisasi. Kepuasan kerja tentunya juga akan mempengaruhi kinerja karyawan. Ketika karyawan merasakan puas dalam pekerjaannya, maka akan berimbas positif terhadap kinerjanya.

Hal ini juga dirasakan dan dilaksanakan di BPS Kabupaten Magelang, namun demikian berdasarkan observasi penulis pada karyawan BPS Kabupaten Magelang, terdapat beberapa permasalahan terkait kinerja karyawan, terutama permasalahan yang terkait dengan kinerja, kedisiplinan, motivasi, dan kepuasan kerja. Masih ditemukan inkonsistensi antara dokumen Kor dan Modul pada Survei Sosial ekonomi Nasional (Susenas). Sehingga akan menghambat proses entri pada pengolahannya. Pada sisi lain, terdapat pula keterlambatan waktu penyelesaian. Terkait kedisiplinan, evaluasi terhadap presensi bisa diukur dengan hand key karyawan. Pada tahun 2015, pimpinan melakukan teguran tertulis terhadap beberapa karyawan yang terbukti memiliki kekurangan jam kerja, dan hal ini juga telah melanggar PP No. 53 Tahun 2010.

Masalah motivasi intrinsik juga terdapat permasalahan, misalnya karyawan masih ada yang kurang termotivasi dalam hal pengembangan diri dan prestasi. Masalah kepuasan kerja juga terdapat permasalahan, masih ada keluhan yang disampaikan yaitu terkait dengan padatnya pekerjaan dalam waktu bersamaan, ada juga yang merasa posisi grade tunjangan kinerja kurang adil. 
Dari paparan di atas, maka peneliti tertarik untuk menguji dan menganalisa pengaruh motivasi intrinsik terhadap kinerja karyawan. Penelitian ini juga akan menganalisa apakah kepuasan kerja dan disiplin kerja merupakan variabel yang memediasi pengaruh motivasi intinsik terhadap kinerja pada Badan Pusat Statistik Kabupaten Magelang

\section{B. Rumusan Masalah}

1. Bagaimana motivasi intrinsik pada Badan Pusat Statistik Kota Tangerang Selatan?.

2. Bagaimana kinerja pegawai pada Badan Pusat Statistik Kota Tangerang Selatan ?.

3. Adakah pengaruh antara motivasi intrinsik terhadap kinerja pegawai pada Badan Pusat Statistik Kota Tangerang Selatan?.

\section{Tujuan Penelitian}

1. Untuk mengetahui kondisi motivasi intrinsik pada Badan Pusat Statistik Kota Tangerang Selatan.

2. Untuk mengetahui kondisi kinerja pegawai pada Badan Pusat Statistik Kota Tangerang Selatan.

3. Untuk mengetahui pengaruh motivasi intrinsik terhadap kinerja pegawai pada Badan Pusat Statistik Kota Tangerang Selatan.

\section{TINJAUAN PUSTAKA}

\section{Motivasi Intrinsik}

Menurut Nawawi (2017:32) memberikan pendapat bahwa motivasi intrinsik adalah pendorong kerja yang bersumber dari dalam diri pekerja sebagai individu, berupa kesadaran mengenai pentingnya pekerjaan yang dilaksanakan atau bisa dikatakan motivasi intrinsik timbul dari dalam diri individu sendiri tanpa ada paksaan atau dorongan orang lain, melainkan atas dasar kemauan sendiri.

\section{Kinerja Pegawai}

Menurut Mangkunegara (2019:75) pengertian kinerja adalah hasil kerja secara kualitas dan kuantitas yang dicapai oleh seorang pegawai dalam melaksanakan tugasnya sesuai dengan tanggung jawab yang diberikan kepadanya.

\section{METODE PENELITIAN}

\section{Populasi}

Yang dijadikan sebagai populasi dalam penelitian ini adalah responden yang berjumlah 85 responden Badan Pusat Statistik Kota Tangerang Selatan

\section{Sampel}

Teknik pengambilan sampling dalam penelitian ini adalah sampel jenuh, dimana semua anggota populasi dijadikan sebagai sampel. Dengan demikian sampel dalam penelitian ini sampel yang digunakan berjumlah 85 responden.

\section{Jenis Penelitian}

Jenis penelitian yang dipakai adalah asosiatif, dimana tujuannya adalah untuk mengetahui atau mencari keterhubungan antara variabel independen terhadap variabel dependennya

\section{Metode Analisis Data}

Dalam menganalisis data digunakan uji validitas, uji reliabilitas, analisis regresi linier sederhana, analisis koefisien korelasi, analisis koefisien determinasi dan pengujian hipotesis. 


\section{HASIL PENELITIAN}

\section{Analisis Deskriptif}

Pada pengujian ini digunakan untuk mengetahui skor minimum dan maksimum skor tertinggi, ratting score dan standar deviasi dari masing-masing variabel. Adapun hasilnya sebagai berikut:

Tabel 1. Hasil Analisis Descriptive Statistics

Descriptive Statistics

\begin{tabular}{lr|r|r|r|r} 
& N & \multicolumn{1}{c}{ Minimum } & Maximum & \multicolumn{1}{c}{ Mean } & \multicolumn{1}{c}{ Std. Deviation } \\
\hline Motivasi intrinsik (X) & 85 & 29 & 44 & 33.96 & 3.965 \\
\hline Kinerja Pegawai (Y) & 85 & 29 & 49 & 38.04 & 4.199 \\
\hline Valid N (listwise) & 85 & & & & \\
\hline
\end{tabular}

Motivasi intrinsik diperoleh varians minimum sebesar 29 dan varians maximum 44 dengan ratting score sebesar 3,396 dengan standar deviasi 3,965. Skor ini termasuk pada rentang sakala 3,40 - 4,19 dengan kriteria baik atau setuju. Kinerja pegawai diperoleh varians minimum sebesar 29 dan varians maximum 49 dengan ratting score sebesar 3,804 dengan standar deviasi 4,199. Skor ini termasuk pada rentang sakala 3,40 $-4,19$ dengan kriteria baik atau setuju.

\section{Analisis Kuantitatif}

Pada analisis ini dimaksudkan untuk mengetahui pengaruh variabel independen terhadap variabel dependen. Adapun hasil pengujian sebagai berikut:

\section{a. Analisis Regresi Linier Sederhana}

Uji regresi ini dimaksudkan untuk mengetahui perubahan variabel dependen jika variabel independen mengalami perubahan. Adapun hasil pengujiannya sebagai berikut:

Tabel 2. Hasil Pengujian Regresi Linier Sederhana

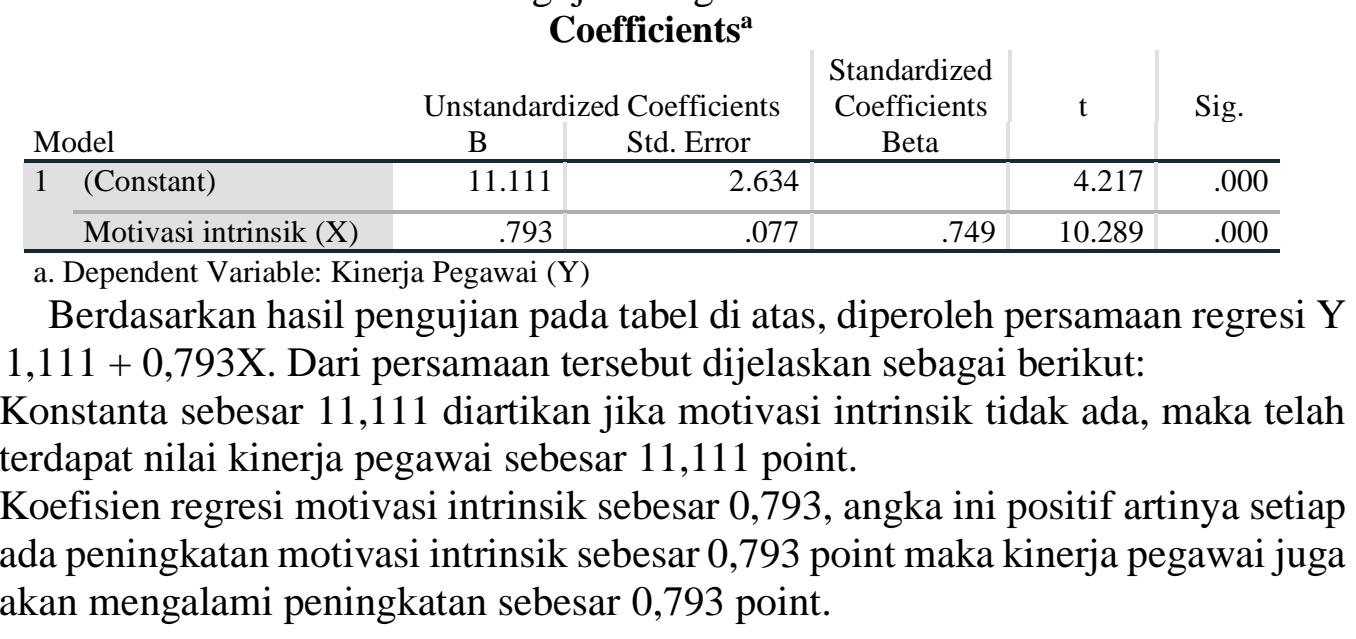

\section{b. Analisis Koefisien Korelasi}

Analisis koefisien korelasi dimaksudkan untuk mengetahui tingkat kekuatan hubungan dari variabel independen terhadap variabel dependen. Adapun hasil pengujian sebagai berikut: 
Tabel 3. Hasil Pengujian Koefisien Korelasi Motivasi intrinsik Terhadap Kinerja Pegawai.

\section{Correlations $^{\text {b }}$}

\begin{tabular}{llr|r} 
& & Motivasi intrinsik (X) & Kinerja Pegawai (Y) \\
\hline Motivasi intrinsik (X) & Pearson Correlation & 1 & $.749^{* *}$ \\
\cline { 2 - 4 } & Sig. (2-tailed) & & .000 \\
\hline Kinerja Pegawai (Y) & Pearson Correlation & $.749^{* *}$ & 1 \\
\cline { 2 - 4 } & Sig. (2-tailed) & .000 & \\
\hline
\end{tabular}

**. Correlation is significant at the 0.01 level (2-tailed).

b. Listwise $\mathrm{N}=85$

Berdasarkan hasil pengujian diperoleh nilai korelasi sebesar 0,749 artinya motivasi intrinsik memiliki hubungan yang kuat terhadap kinerja pegawai.

\section{c. Analisis Koefisien Determinasi}

Analisis koefisien determinasi dimaksudkan untuk mengetahui besarnya persentase pengaruh dari variabel independen terhadap variabel dependen. Adapun hasil pengujian sebagai berikut:

Tabel 4. Hasil Pengujian Koefisien Determinasi Motivasi intrinsik Terhadap

Kinerja Pegawai.

Model Summary

\begin{tabular}{|c|c|c|c|c|}
\hline \multicolumn{5}{|c|}{ 20 } \\
\hline Model & $\mathrm{R}$ & R Square & $\begin{array}{l}\text { Adjusted R } \\
\text { Square }\end{array}$ & Std. Error of the Estimate \\
\hline 1 & $.749^{\mathrm{a}}$ & .561 & .555 & 2.800 \\
\hline
\end{tabular}

a. Predictors: (Constant), Motivasi intrinsik (X)

Berdasarkan hasil pengujian diperoleh nilai determinasi sebesar 0,561 artinya motivasi intrinsik memiliki kontribusi pengaruh sebesar 56,1\% terhadap kinerja pegawai, sedangkan sisanya sebesar $43,9 \%$ dipengaruhi oleh faktor lain yang tidak dilakukan penelitian.

\section{d. Uji Hipotesis}

Pengujian hipotesis dengan uji t digunakan untuk mengetahui hipotesis mana yang diterima. Rumusan hipotesis: Terdapat pengaruh yang signifikan motivasi intrinsik terhadap kinerja pegawai.

Tabel 5. Hasil Uji Hipotesis Motivasi intrinsik Terhadap Kinerja Pegawai.

\begin{tabular}{|c|c|c|c|c|c|}
\hline \multirow[b]{3}{*}{ Model } & \multicolumn{3}{|c|}{ Coefficients $^{\mathrm{a}}$} & \multirow[b]{3}{*}{$\mathrm{t}$} & \multirow[b]{3}{*}{ Sig. } \\
\hline & \multicolumn{2}{|c|}{$\begin{array}{l}\text { Unstandardized } \\
\text { Coefficients }\end{array}$} & \multirow{2}{*}{$\begin{array}{c}\text { Standardized } \\
\text { Coefficients } \\
\text { Beta }\end{array}$} & & \\
\hline & $\mathrm{B}$ & Std. Error & & & \\
\hline $1 \quad$ (Constant $)$ & 11.111 & 2.634 & & 4.217 & .000 \\
\hline Motivasi intrinsik (X) & .793 & .077 & .749 & 10.289 & .000 \\
\hline
\end{tabular}

Berdasarkan hasil pengujian pada tabel di atas, diperoleh nilai thitung $>\mathrm{t}$ tabel atau $(10,289>1,989)$, dengan demikian hipotesis yang diajukan bahwa terdapat pengaruh yang signifikan atara motivasi intrinsik terhadap kinerja pegawai diterima.

\section{Pembahasan Hasil Penelitian}

\section{Kondisi Jawaban Responden Variabel Motivasi intrinsik}

Berdasarkan jawaban responden, variabel motivasi intrinsik diperoleh ratting score sebesar 3,396 berada di rentang skala 3,40 - 4,19 dengan kriteria baik atau setuju.

\section{Kondisi Jawaban Responden Variabel Kinerja Pegawai}

Berdasarkan jawaban responden, variabel kinerja pegawai diperoleh ratting score 
sebesar 3,804 berada di rentang skala 3,40 - 4,19 dengan kriteria baik atau setuju.

\section{Pengaruh Motivasi intrinsik Terhadap Kinerja Pegawai}

Motivasi intrinsik berpengaruh signifikan terhadap kinerja pegawai dengan persamaan regresi $\mathrm{Y}=11,111+0,793 \mathrm{X}$, nilai korelasi sebesar 0,749 atau memiliki hubungan yang kuat dengan kontribusi pengaruh sebesar 56,1\%. Pengujian hipotesis diperoleh nilai thitung $>\mathrm{t}$ tabel atau $(10,289>1,989)$. Dengan demikian hipotesis yang diajukan bahwa terdapat berpengaruh signifikan antara motivasi intrinsik terhadap kinerja pegawai diterima.

\section{KESIMPULAN DAN SARAN}

\section{Kesimpulan}

a. Variabel motivasi intrinsik diperoleh ratting score sebesar 3,396 berada di rentang skala 3,40-4,19 dengan kriteria baik atau setuju.

b. Variabel kinerja pegawai diperoleh ratting score sebesar 3,804 berada di rentang skala 3,40 - 4,19 dengan kriteria baik atau setuju.

c. Motivasi intrinsik berpengaruh signifikan terhadap kinerja pegawai dengan persamaan regresi $\mathrm{Y}=11,111+0,793 \mathrm{X}$, nilai korelasi sebesar 0,749 atau kuat dan kontribusi pengaruh sebesar 56,1\% sedangkan sisanya sebesar 43,9\% dipengaruhi faktor lain. Uji hipotesis diperoleh nilai t hitung > t tabel atau $(10,289>1,989)$.

\section{Saran}

a. Pimpinan harus mampu memberikan motivasi dengan mendorong pegawai agar mampu bekerja secara optimal yang tumbuh dari dalam diri pekerja sebagai individu

b. Lembaga harus selalu memberikan semangat dan apresiasi yang layak untuk memastikan pegawai memiliki semangat kerja yang tinggi.

\section{DAFTAR PUSTAKA}

Abdullah. M (2014). Manajemen dan Evaluasi Kinerja Pegawai. Yogyakarta: Penerbit Aswaja Pressindo.

Algifari. (2015). Analisis Regresi untuk Bisnis dan Ekonomi. Yogyakarta: BPFE.

Arikunto, Suharsimi (2014). Prosedur Penelitian Suatu Pendekatan Praktek. Jakarta: Rineka Cipta.

Bangun, Wilson. (2012). Manajemen Sumber Daya Manusia. Jakarta: Erlangga

Bejo Siswanto (2013) Manajemen Tenaga Kerja Rancangan dalam Pendayagunaan dan Pengembangan Unsur Tenaga Kerja. Bandung: Sinar Baru.

Dessler, G. (2006.). Manajemen Sumber Daya Manusia. Jilid II. Jakarta: Indeks.

Edi Sutrisno (2016). Manajemen Sumber Daya Manusia. Jakarta: Prenadamedia Group.

George Terry R \& Rue, Leslie W. Rue (2016). Dasar-Dasar Manajemen. Jakarta Bumi Aksara.

Gerry Dessler (2016). Human Resources Management. Prenticehall. London: International Inc.

Handoko (2016). Manajemen Personalia dan Sumberdaya Manusia. Yogyakarta: BPFE.

Hasibuan, Malayu S.P. (2016). Manajemen Sumber Daya Manusia. Edisi Revisi. Jakarta: PT Bumi Aksara.

Imam Ghozali (2017). “Aplikasi Analisis Multivariate Dengan Program SPSS”. Edisi Kelima. Semarang: Badan Penerbit Undip.

Istijanto (2014) "Riset Sumber Daya Manusia". Jakarta: PT. Gramedia Pustaka

Kharis, Ismu Fadli (2011). Studi Mengenai Impulse Buying dalam Penjualan Online. 
Semarang : Skripsi Universitas Diponegoro

Luthans Fred (2014). Organizational Behavior. Ney York: McGraw-Hill. New York.

Mangkunegara, Prabu Anwar. (2016). Evaluasi Kinerja SDM. Cetakan ke tujuh, PT Refika Aditama: Bandung.

Rao, Purba, (2012). Measuring Consumer Perceptions Through Factor Analysis. The Asian.

Robbins, P.S, \& Judge, A.T. (2003). Organizational Behavior. Jakarta: Salemba Empat.

Santoso, Singgih (2015). Menguasai Statistik Multivariat. Jakarta: PT Elex Media Komputindo.

Sedarmayanti (2016) Manajemen Sumber Daya Manusia, Reformasi Birokrasi dan Manajemen Pegawai Negeri Sipil, Cetakan Kelima, Bandung: PT Refika Aditama.

Sudjana (2014). Metode Statistika. Bandung: Tarsido.

Sugiyono (2017). Metode Penelitian Administrasi dilengkapi dengan Metode R \& D. Bandung: Alfabeta.

Veithzal Rivai (2015) Manajemen Sumber Daya Manusia Untuk Perusahaan. Jakarta: Raja Grafindo Persada.

Wibowo (2015). Manajemen Kinerja. Jakarta: PT. Raja Grafindo Persada. 